\title{
The Study of current Biomass Energy Policy in China and
}

\section{Several Recommendations}

\author{
Xueying Ding \\ NORTH CHINA ELECTRIC POWER UNIVERSITY, Baoding 071000, China
}

1476848927@qq.com

\begin{abstract}
In this paper through a study of the current domestic biomass energy policy in China, we can see that China's policies on biomass energy includes:1) Relevant laws, 2) Priority access system, 3) Fixed price. After that, combined with foreign successful experience, the following four recommendations are given: 1)construct Characteristic Industry Chain; 2)improve the price subsidy policy; 3)increase government investment, expand funding channels; 4)cultivate high - tech talent, put emphasis on R \& D. As long as we are determined to regard biomass energy as the core to establish the national energy system of independent security and stability, goals of sustainable development can be achieved in the future.
\end{abstract}

Keywords: Biomass Energy Policy Priority access system Fixed price Recommendations

\section{Introduction}

The global fossil energy has been running out with the rapid development of modern economy. The earth is facing the problems of shortage of resources and pollution emission. Therefore, the urgent actions to solve the current energy crisis and environmental problems are to look for renewable energy and research clean conversion technology. Biomass energy has been paid more and more attention by many countries because of its low pollution, renewable capability, extensive distribution and abundant quantity. It has become one of the fastest growing technologies in the world in recent years.

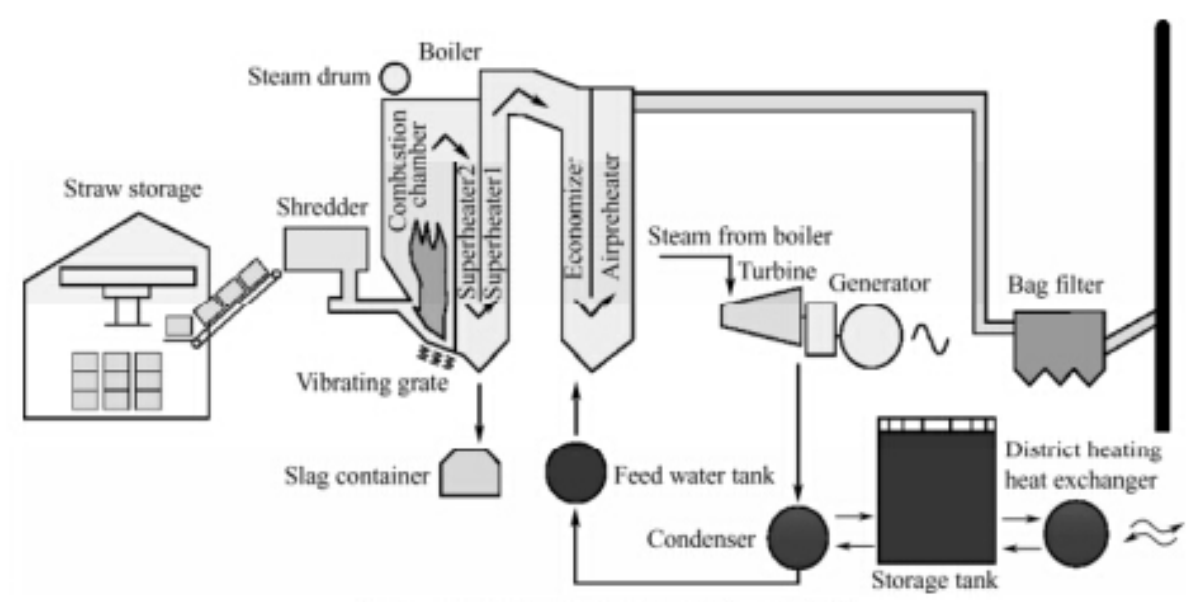

Figure1. the flow chart of straw power 
Power generation by biomass includes direct combustion, gasification combustion, mixed fuel project and so on. The direct combustion of biomass, the most important way of biomass utilization at present, refers to feeding the biomass into boiler for combustion, and producing steam by heat, then driving steam turbine to work and generator to generate electricity. The fuels of biomass power generation include straw, corn husks, wood, living garbage and so on. At present, straw power generation develops rapidly in China. The specific process shown in Figure1. Research shows that biomass power generation can reduce greenhouse gas emissions by $83 \%$ compared with coal-fired power generation [1].

\section{Relevant policies in China}

Biomass energy is rich in China, which is of great significance to the sustainable development of society. However, the development and utilization of biomass energy in our country is still in the initial stage, and there are various shortages to improve. Therefore, the relevant policies in China play very important roles in the development of biomass energy.

\section{1) Relevant laws}

In 1995 the electric power law of P.R.C clearly points out that the use of new energy, renewable energy and clean energy is supported in China, and the use of new energy and renewable energy is very important. In 2006, Renewable Energy Law was promulgated, which defines the status of renewable energy in the national energy development, but also the definition of biomass energy. Fourth of the law provides that the development and utilization of renewable energy are regard as the priority areas of energy development. It also encourages the development of biomass energy in rural, including encouraging the utilization of clean and efficient biomass fuel, the cultivation of energy crops and the extension of renewable energy in line with local conditions. In 2007, the Energy Conservation Law promulgated provides that our country encourages the development of biogas in rural areas, promotes the use of renewable energy technologies such as solar energy, wind energy and biomass energy, orderly develops small hydropower in accordance with the principle of scientific planning , and promotes energy saving rural houses and stoves etc.

\section{2) Priority access system}

Renewable Energy Law provides the grid corporations shall sign grid protocol with the renewable energy power generation enterprises who have obtained administrative license or submitted for the record, and acquire the grid electricity of the renewable energy power generation project in the grid coverage. Besides, they also provide the service for the renewable energy power generation.

\section{3) Fixed price}

The price of biomass power generation standard in China is composed by the traditional prices indifferent provinces and subsidies of governments, and electricity subsidy standard is 0.25 yuan/ $\mathrm{KW} \cdot \mathrm{h}$ at present. In addition, biomass-and-coal mixed firing project doesn't enjoy the subsidy when heat consumption of coal is more than $20 \%$. 


\section{Suggestions for biomass energy policies}

Western countries such as the US, Brazil, have made great achievements in the technical research and industrial model of biomass energy. Biomass power generation in China also develops rapidly, it is far behind western countries, however. Through studying about the foreign related policies, several suggestions are put forward below:

\section{1) Construct Characteristic Industry Chain}

Drawing lessons from the successful experience of foreign biomass energy industry, the characteristic industrial chain of straw power generation in China can be formed. Use straw and other "green energy" as fuels to generate power, while the heat is provided for the neighbor, and ash is provided to the nearby fertilizer plant as materials, the recycling economy industrial chain of biomass - electricity - heat chemical is formed.

\section{2) Improve the price subsidy policy}

We all know that biomass and coal mixed combustion project can not only save the operating costs, but also reduce emissions of harmful gases, such as $\mathrm{NO}_{x}$ and $\mathrm{SO}_{2}$. Therefore, the current price subsidy policy in China greatly limits the promotion of biomass-and-coal mixed firing program with good economic and environmental benefits. Therefore, the biomass-and-coal mixed firing program can enjoy subsidies based on the amount of burning straw.

\section{3) Increase government investment, expand funding channels}

Support for renewable energy is different for different countries. For example, England improves investment by levying carbon taxation and fuel taxation[2], Indian government provides $10 \%$ to $15 \%$ of its equipment cost for renewable energy companies[3] , and the US reduces fuel consumption tax on gas oil which is mixed with bioethanol[4-5].So our country can follow these measures, as a guarantee for long-term investment about biomass power generation. At the same time, distinguish the priorities of investment. In the case of certain funds, put technology research in the first place.

\section{4) Cultivate high - tech talent, put emphasis on $R \& D$}

Lack of innovative talent and research platform is one of the bottlenecks restricting the development of biomass power generation. Therefore, the biomass energy research center and the specialized laboratory must be established, and provide good hardware and software environments for professionals to participate in R \& D activities .

\section{Conclusions}

We first summarize on the current biomass energy policies in the above content, and then put forward suggestions for improvement, so that the development of biomass energy industry in China is more stable and healthy.

Biomass energy will become an important part of sustainable energy in the future century. The fossil energy resources are limited in China, but the territory is vast. So our country is rich in biomass resources. The development of biomass energy has important strategic significance and practical significance. Facing the increasingly 
strengthened resources and environment constraints, we must strengthen the awareness of the crisis, establish a green, low-carbon development concept, and focus on energy-saving emission reduction to improve sustainable development capacity. We must significantly reduce the energy consumption intensity and carbon dioxide emissions as a binding indicator to effectively control emissions of greenhouse gas. Reasonable control of the total energy consumption, inhibit the rapid growth of high energy-consuming industries to improve energy efficiency. The use of high-tech technology converts straw, livestock manure and organic wastewater and other biomass into high-grade energy. The development of biomass energy to create a useful development environment will be involved in rural development, energy development, environmental protection, resource protection, national security and ecological balance and many other benefits. As long as the state is determined to regard biomass energy as the core to establish the national energy system of independent security and stability, goals of sustainable development can be achieved in the future.

\section{References}

[1]RoderM, Whittaker C,Thomley P.How certain are greenhouse gas reductions from bioenergy? Life cycle assessment and uncertainty analysis of wood pellet-to-electricity supply chains from forest residues[J]. Biomass and bioenergy,2015.

[2]Gorter H D, Just D R.The economics of a blend mandate for biofuels [J] .Agriculture Economics, 2009, 91(3): $738-750$.

[3] Piyush Joshi,Neeta Sharma,Priyangshu Manab Sarma.Assessment of Biomass Potential and Current Status of Bio-fuels and Bioenergy Production in India[J].Current Biochemical Engineering, 2016.

[4]Koplow D, Track E.Biofuels-At What Cost [R] .Government Support for Ethanol and Biodiesel in the United States.2007 Update. http: / / www.global subsidies. Org / files / assets / pdf / Brochure _ _ _US_Report.pdf October 2007.

[5]Koplow D, Track E.Biofuels-At What Cost [R]. Government Support for Ethanol and Biodiesel in the United States, October 2006. http: / / www.global subsidies. org / files / assets / pdf / Brochure _ _ _US_Report. pdf October 2006. 